\title{
STUDENT RESEARCH PROJECTS WITH INDUSTRIAL IMPACT
}

\author{
S.D. Grimshaw, C.J. Clark, J.V. Taylor \\ Whittle Laboratory \\ University of Cambridge \\ 1 JJ Thomson Avenue \\ Cambridge, CB3 ODY, UK \\ Email: sdg33@cam.ac.uk

\section{R. Spataro} \\ Reaction Engines Ltd \\ Culham Science Centre \\ Abingdon, OX14 3DB, UK
}

\begin{abstract}
This paper describes six final year undergraduate research projects supported by a collaboration between the Whittle Laboratory at the University of Cambridge and Reaction Engines (RE), a UK aerospace company. The collaboration is now in its fourth year of projects relating to RE's Synergetic Air Breathing Rocket Engine (SABRE).

The approach taken in these projects combines modern teaching pedagogy with a best practice methodology for industrial-academic collaboration and a well established framework for structuring research problems. This paper explains how the three methodologies are tailored and adapted for use with final year undergraduate research projects.

The approach is mapped on to an annual project cycle which begins with the industry and academic partners deciding which topics to investigate and proceeds through student selection, the project work itself and concludes with student assessment and end-of-year reporting. The projects combine analytical, computational and experimental work and have covered counter-rotating turbomachinery, S-ducts in compressors and Helium Turbine design, all of which are topics of primary importance to the design of SABRE.

Following descriptions of each of the six completed projects, the impact of the work and lessons learned are considered from the point of view of the students, the industrial partner and the academic supervisors. Overall, the students found the work extremely engaging and have all been encouraged to pursue careers in engineering, either in industry or through post-graduate study. For the industry partner the collaboration provides expertise and an approach which is not available in-house as well providing a 'second look' at key technical questions. For the
\end{abstract}


academics involved, the opportunity to lead research on a 'real' problem with an industrial partner has proved highly motivating as well as providing opportunities for personal and career development.

\section{INTRODUCTION}

Since 2017, academics at the Whittle Laboratory have worked with Reaction Engines (RE), a UK-based aerospace technology company, to run student research projects investigating the design of the Synergetic Air Breathing Rocket Engine (SABRE). These projects aim to maximise educational benefit to the students, provide useful results for the industrial partner, and engage and motivate the academics supervising the work.

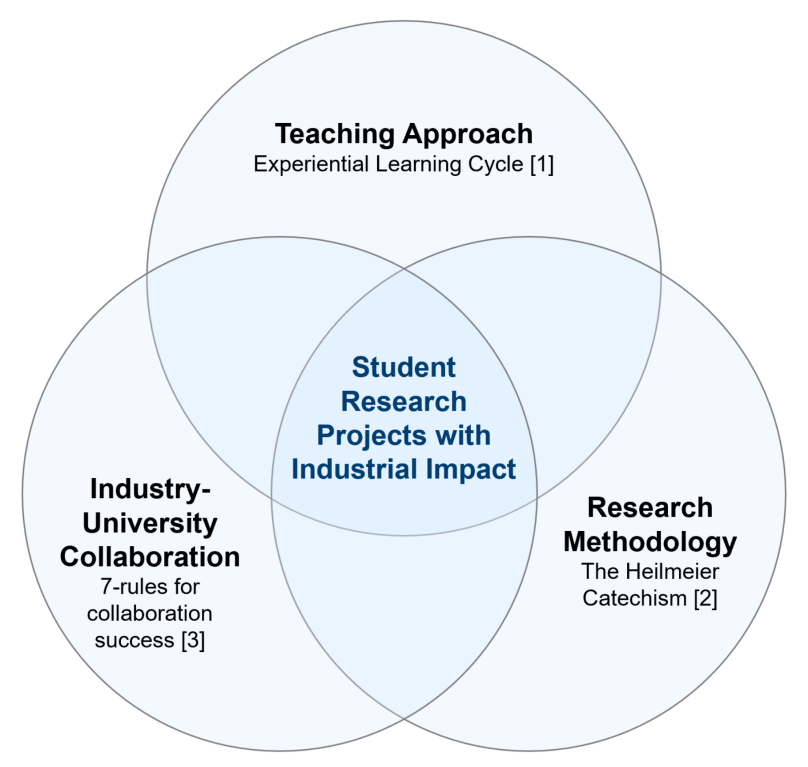

Fig. 1: Approach combining established methodologies for teaching [1], research [2] and collaboration [3].

This paper presents an approach which achieves the aims by combining and adapting established practices in Teaching Pedagogy, Industrial-Academic Collaboration and Research Methodology, as shown in Fig. 1. It goes on to describe six research projects completed between 2017 and 2020 which illustrate how the approach in Fig. 1 has been applied in practice. These projects combine experimental work and computational fluid dynamics (CFD), focus on real-world turbomachinery design problems and are linked from year-to-year with a new student continuing from the previous one. Finally, the impact of the projects is investigated in relation to not only the students, but also the industrial partner and the academic supervisors. An emphasis is placed on the development of all of the participants and the lessons learned through participating in the collaboration.

The students undertaking the research projects are in the final year of the University of Cambridge Engineering Department's (CUED) Integrated Masters in Engineering (MEng) which extends undergraduate studies to Masters level through a four-year degree. The overall course structure is shown in Fig. 2; students progress from a 'general' syllabus in the first two years which covers mechanics, structures, materials, fluid dynamics, thermodynamics, electrical engineering, electronics, information, control and mathematics, to a more 'specialised' course in years three and four where students choose an 'engineering area' such as aerospace and aerothermal engineering. Each academic year has three terms, two of eight weeks 
and one of seven weeks which includes an examination period.

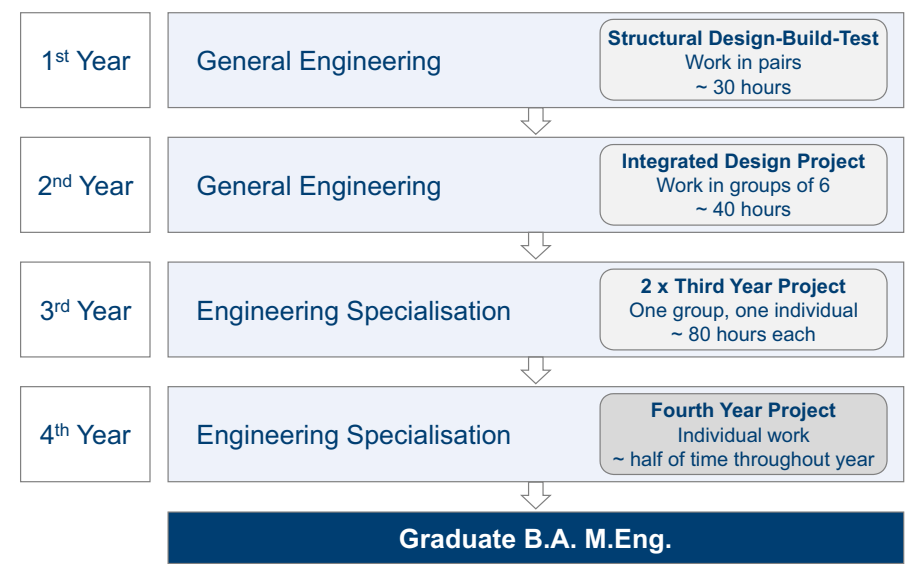

Fig. 2: University of Cambridge Engineering Department's (CUED) Integrated Masters in Engineering (MEng) Course Structure.

In the first three years of the degree, students undertake approximately 4 hours of practical laboratory work per week which builds on and reinforces the material taught in lectures. These years also include extended projects, shown in Fig. 2, which challenge the students to work on more 'open-ended' problems: in first year this is a structural design-build-test, in second year an integrated mechanical, electronic and software engineering project, and in third year the students complete one group and one individual research or design project chosen from a list of approximately 30.

The 'Fourth Year Project', completed in the final year of study, is expected to take up approximately half of a student's working time and must include one or more elements of design, research or computation. All fourth year projects have 'novel problems' where the answer is not known at the start of the work. The projects are intended to stretch the students and give them the opportunity to demonstrate that they have reached the MEng standard. Each project is supervised by an academic who is responsible for guiding and supporting the student's work. The student is assessed through written reports and oral presentations by two academics, one of which is the project supervisor and one who is independent. Marks are also given by the supervisor for each term's progress and industry.

A wide range of project topics are available and fields of study in the Energy, Fluid Mechanics and Turbomachinery Division (Division A) include: CFD, Design Optimisation, Energy, Combustion, Fluid Mechanics, Aeronautics and Turbomachinery. A similar breadth is offered by the other divisions in CUED (Electrical Engineering; Mechanics, Materials and Design; Civil, Structural and Environmental Engineering; and Information Engineering). Within Division A 63 projects were offered for the 2020-21 academic year, and 16 of these are supervised by academics working at the Whittle Laboratory. At the Whittle Laboratory approximately $50 \%$ of the projects are linked to industry partners with $25 \%$ (including the RE projects) directly funded by industry.

Reaction Engines is a privately held technology company based in Culham, Oxfordshire, UK and employs over 200 staff across its sites in the UK and US. The company is supported by the UK Government, UK Space Agency and European Space Agency and its US team are working with US Government and industry partners.

SABRE, shown in Fig. 3, is being developed by RE for use with high speed aircraft and spacecraft. In air-breathing mode, high pressure air is fed to the SABRE rocket combustion chamber via an intake, air pre-cooler and turbo-compressor. 


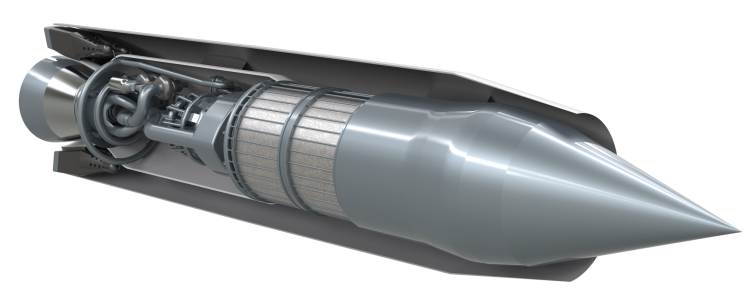

Fig. 3: Reaction Engines Synergetic Air Breathing Rocket Engine - SABRE

At speeds in excess of Mach 5, the intake is closed and the engine switches to operation as a conventional high-performance rocket which can accelerate the vehicle to orbital speed [4].

\section{UNIVERSITY RESEARCH AND DESIGN PROJECTS}

Many university engineering courses culminate in an extended research or design project which students undertake in their final year of study. It is widely accepted these projects are a crucial part of students' education which closes the gap between theory learned in lectures and assessed by exam, and the reality of the engineering profession in practice. For example, Rumpfkeil et al. [5] state that a "more learner-centred teaching style ... is fueled by the need for future engineers to demonstrate the use of higher order thinking, problem solving, and more interpersonal aspects ... such as communication, social and team-work skills." Similarly, Vo and Trepanier [6] comment that “...engineering education has moved away from an overwhelming emphasis on teaching engineering science to accentuating both engineering fundamentals and engineering practice for making new graduates more adept at solving real-world engineering problems in an industrial context." More succintly, Wisler [7], in discussing multi-disiplinary design courses, states that "these projects require the kind of thinking that will serve you well in industry." .

\section{Types of Student Project}

Final year research or design projects, relating to propulsion and power applications, can be split into two categories: The first group [5,8-13] have 'simulated problems' so that the projects offer students a realistic experience of engineering in industry but do not attempt to solve an unanswered problem. The second type of project $[6,14-17]$ have 'novel problems' meaning that the student addresses a research question or design challenge, often posed by an industrial partner, to which the answer is not known.

An example of the simulated problem type is reported by Mund et al. [9] where a team of German, French and Swiss students collaborated on the multi-component, multi-disciplinary design of a gas turbine system including the high-pressure compressor, the secondary air system and the cooled, high-pressure turbine. Industry professionals were involved in mentoring the students, however, the benefits discussed are in relation to the students' education and any positive impacts for the industrial partners are not reported. Other projects of this type include a turbo generator design project at Imperial College in the UK [8], a thrust vectoring design project across six universities with support from the United States Air Force [5, 11], an interdisciplinary design project for an unmanned air vehicle [10], a preliminary aircraft engine design process looking at multidisciplinary trades [12] and a gas turbine multidisciplinary conceptual design given a set of functional requirements [13].

Each of these projects is focused on a different challenge, however, they share a number of characteristics: they are all multidisciplinary, all are performed in teams, and industrial collaboration comes in the form of mentoring and sharing 
of expertise $[8,9,12]$, site visits $[8,9,11]$ and involvement in design reviews and final presentations $[9,10,12]$. Four of the projects also include competition between teams [10-13] and while not stated explicitly, it is hypothesised that the competitive element was used to motivate the students and simulate some of the pressure felt in a real industrial setting. Where they are reported, the lessons learned are also similar: Mund et al. [9], Pullen et al. [8] and Kyprianidis et al. [13] all highlight challenges with communication and team dynamics and the large team projects [8,9] also found issues with the interfaces between disciplines (e.g. aerodynamics and mechanics) and across sub-teams. In summary, the simulated problem project type is well-suited to situations with teams of students, where industry involvement can be advisory and where a systems level or multidisciplinary understanding is a desired learning outcome.

The projects run at the Whittle Laboratory in collaboration with RE are of the novel problem type; they include a research question or design challenge to which the answer is not known and if successful, can have an impact beyond the beneficial educational experience of the students. In the literature, Mirzamoghadam and Harding [14] describe student projects sponsored by Honeywell which design, build, test and improve a heat transfer measurement rig over several years, Lock et al. [17] report undergraduate design exercises carried out with Rolls-Royce, Biba and Maier [16] present an undergraduate project in collaboration with Dresser-Rand to develop a stage design tool for centrifugal compressors, and Vo and Trepanier [6] describe undergraduate projects where 3-D printed compressor rigs are designed, manufactured and used for stall research. In contrast to the simulated problem work, these projects tend to focus on specific research questions or component design challenges rather than on systems-level design. They do not require the element of competition because student motivation is maintained by having to deliver a useful outcome to a sponsor.

\section{Lessons Learned}

Some papers consider the lessons learned and impact of collaborations for the industry partner. Mirzamoghadam and Harding [14] emphasise the importance of the industry partner providing a contact who can work closely with the university and students. They also observe that two of the participant students have gone on to be hired by Honeywell. However, despite demonstrating a close collaboration, it is not clear from the paper whether the research could be used in practice by the industry partner. Lock et al. [17] list the benefits to Rolls-Royce as: "Cost-effective method for project activities, potential recruitment path, extended period for activity with sponsored students, involvement with university". There is also a section describing the Rolls-Royce perspective which indicates that the projects have a positive technical impact even to the extent that one of the projects is not discussed for proprietary reasons. The projects described by Vo and Trepanier [6] are not industry sponsored, however, they have led to technical publications on compressor stall suppression demonstrating another way in which student research projects can have impact beyond their educational benefits. In this paper the project manager at RE reflects on the collaboration to date, explains how the partnership has developed and describes the technical impact of the students' work.

In addition to the students and industry partners, the academics who supervise the projects are key participants. Their role in student education and the impact of the work on their personal and career development is usually overlooked in the literature. Miller et al. [15] make a rare assessment of the benefits to faculty participants which includes a better understanding of technical issues, a recognition of real life problems, experience in initiating and executing a collaborative project and establishment of a technical infrastructure for future work. Lock et al. [17] also note the benefits to the student supervisor at Rolls-Royce include the "experience and freedom to guide a project". In this paper, the challenges and benefits for the academics who supervise student projects with industry collaboration are considered. 
The combined approach shown in Fig. 1 is reminiscent of that presented by Acworth in a paper about the Knowledge Integration Community (KIC) at the Cambridge-MIT Institute which "unites research, education and industry stakeholders" [18]. However, the work described by Acworth relates to a "grand and overarching scheme" and is discussed at a high level where as this paper presents a practical approach for industrial collaboration on individual student projects. None of the papers reviewed report such an approach and it is hoped that this paper will be useful for engineers, both in academia and industry, who are considering how to run student projects with industrial collaboration.

\section{INDUSTRY COLLABORATION RESEARCH APPROACH}

The Whittle Laboratory collaboration with RE began with a meeting in September 2016 to discuss ideas for research topics for student projects. The first project started in July 2017 and since then six have been completed and a seventh is currently in progress. While running these projects an approach has been developed which combines teaching pedagogy, research methodology and best practice for industry-university collaboration, as shown in Fig. 1. In this section the three aspects of the approach are examined.

\section{Teaching Approach}

The Fourth Year Project is the largest single component of the CUED undergraduate degree and its general aims, listed by the department, are to enable students to:

- Undertake a major piece of connected work of engineering significance.

- Learn how to conduct efficient literature surveys, appreciate problems with planning, and exercise initiative in a technical context.

- Develop skills in modelling and analysis in situations where appropriate assumptions are not known $a$ priori.

- Build design skills, including the design of experiments.

- Report a major piece of technical work.

The project supervisors have a responsibility to ensure that these aims are met and the project experience is of high educational value for the student. A second goal is to inspire the students to want to pursue a career in engineering.

While developing the Teaching Approach it is useful to consider a Theory of Learning. Kolb [1] provides a model for how students build knowledge called the 'Experiential Learning Cycle'. In addition, Morss and Murray [19] suggest that 'Motivation' should be placed at the centre of the cycle so that students drive themselves from stage to stage. From experience it is observed that this model, shown in a modified form in Fig. 4, accurately captures the way that successful students learn during their fourth year projects. Vo and Trepanier [6] mention the importance of experiential learning but none of the papers described above give details of how a teaching approach can ensure students learn this way.

Kolb's Theory of Learning provides a foundation on which to build the teaching approach. Weekly 1-hour meetings between the supervisor and student form the back bone of the project and an agenda has developed which follows the Experiential Learning Cycle: First, the student describes or presents the work carried out during the last week and is encouraged to reflect on what they have learned or difficulties they have had; this represents the first two stages of the cycle, i.e. experience, and observing and reflecting. The supervisor then helps the student to consider what they have learned in the wider context of the project, i.e. to form concepts and generalisations: how does their work fit in with previous ideas they have had? Is progress still being made towards the overall goal of the project? How do the results help decide what to do next? Finally, 


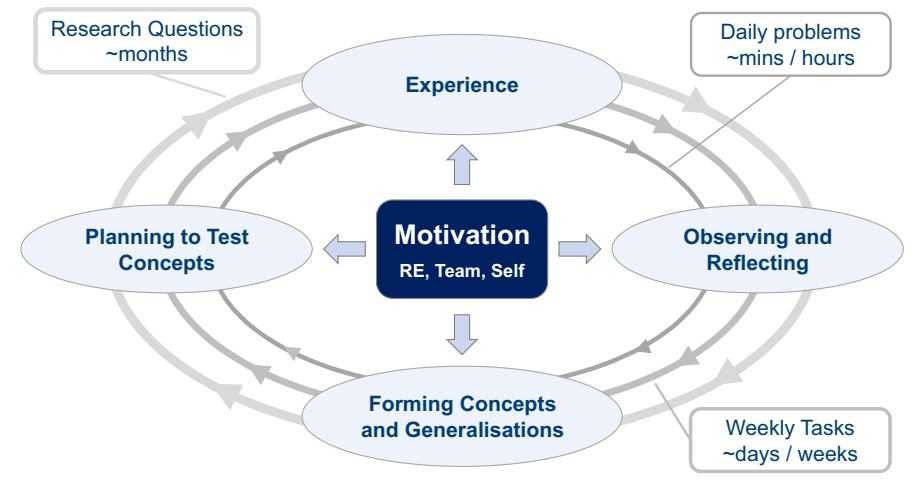

Fig. 4: Experiential Learning Cycle, adapted from Kolb [1] to show how students pass around the cycle on different time scales.

based on the discussion, a plan is drawn up for the next week of work including contingencies in case an action cannot be completed. Meeting discussions and actions are recorded by the students in a log book and the supervisors take notes which are referred to when allocating progress and industry marks.

This teaching approach is also adopted in day-to-day interactions: students are encouraged to solve problems by 'trying things out', asking questions, considering assumptions and making links to the material they have learned throughout their degree. This means that the students are constantly proceeding around the Experiential Learning Cycle on different time scales, as represented in Fig. 4, varying from minutes or hours for small, simple problems up to weeks and months required to answer the questions fundamental to the research project.

The Teaching Approach described here also draws upon and is consistent with another 'learner-centred' methodology called Constructive Alignment (Biggs [20], Moon [21]). Aims, activities and assessment are aligned so that students know what is to be achieved, what activities will be undertaken to accomplish the aims and how they will be assessed. This is particularly useful for helping the students to keep sight of the 'bigger picture': overall project aims or research questions need to guide their work, the activities they carry out should work towards these aims, and deadlines are in place for interim and final presentations and reports on which they are assessed. Giving clear goals and explaining how these will be met is a crucial element in maintaining student motivation. For report writing and presentations an emphasis is placed on establishing a simple, linear structure which includes motivation for the work, well-written, quantified discussion of results and concise conclusions which link back to the aims of the project.

Combining student projects with industrial engagement and open research problems requires some specific elements to be included in the teaching approach. At the start of the project the challenge of addressing a real industrial research question, which goes beyond the CUED course syllabus, can be daunting for the students. At this stage the supervisor helps and encourages the student to move around the cycle with manageable problems which are set as weekly actions. This requires the supervisor to think carefully about the problem and to develop a plan for the start of the work which is appropriate for the student. As the project progresses and the student passes around and around the Experiential Learning Cycle they get used to the process and begin to build technical understanding. After six to eight weeks it is observed that students can 'self-sustain' the cycle so that progress increases and they are able to make their own decisions about findings and next steps.

Contact between the students and industry representatives is managed by the academic supervisors and generally limited to termly presentations. Technical data is transferred between RE and the academics and administrative matters such as non- 
disclosure agreements and contracts are managed by the academics and university support staff. This ensures that the students can focus on engineering problems, that lines of communication within the collaboration are clear, and that responsibility for the students' supervision always lies with the academics. The termly presentations to RE provide significant motivation; contact with the professional engineers in the company sets tangible deadlines and encourages the students to practice and develop their presentation skills. Also, at least one of the presentation sessions each year occurs at RE's headquarters in Oxfordshire so the students are able to participate in a tour of the company's facilities.

\section{Research Methodology}

A successful Research Methodology has been developed which supports the Teaching and Collaboration Approaches and is able to address industrially relevant problems. This methodology can be split into four principles: selecting the right problem, working with pace and simplicity, using the correct tools and working in small, focused teams.

Selecting the research problem. Picking the right problem is key as it sets, at an early stage, the likelihood of project success and the impact of the research. A useful set of criteria for project selection are found in the 'Heilmeier Catechism' shown in Fig. 5. These questions were devised by George Heilmeier to help DARPA officials evaluate proposed research programs [2]. Questions 1-3 aim to identify the research question, compare it to current practice and isolate the new elements of the proposed approach. Question 4 ensures the research has a specific, tangible output, and Questions 5-7 ensure the scope is feasible and the main risks to the success of the project are understood. The final question starts to form the structure of the work by setting milestones which are relevant to the project's success.

The research scope must be appropriate for the time available and with students this can be difficult to judge in advance. Experience shows that the best approach is to initially adopt a basic scope which can expand if the student makes good progress. Rather than tying milestones to the completion of certain tasks, they are linked to sub-research questions, whose answers are required to progress towards the overall goal. It has been the authors' experience that time invested thinking about and answering the Heilmeier Catechism questions, in an honest and detailed manner, is an excellent first step in ensuring project success.

Pace and simplicity. For research to progress at pace, the rate at which ideas are selected, tested and evaluated should be on a human time scale, i.e. of the order days, hours or even minutes, not weeks or months. Only by moving this quickly can a problem be understood deeply and across multiple dimensions. The second aspect of this principle is that the simplest route to an answer should always be sought. Addressing Questions 1-3 of the Heilmeier Catechism help identify the important research questions and this prevents unnecessary, time consuming tests or simulations being undertaken without a focused aim. Overall, to achieve pace and simplicity careful thought and planning is required to develop rapid experimental tests or focused simulations which directly address the problem.

Using the correct tool. In aerodynamics and turbomachinery research there are a range of methods to investigate a problem and these can be broadly categorised into:

- Theory and low order analytical models

- CFD of differing fidelities

- Stationary and rotating experiments

For each research question the use of different tools should be evaluated using the accuracy of the answer and the speed by which it is obtained as metrics for selection; a tool should not be selected just because it is 'familiar'. This results in 
1. What are you trying to do? Articulate your objectives using absolutely nojargon.

2. How is it done today, and what are the limits of current practice?

3. What is new in your approach and why do you think it will be successful?

4. Who cares? If you are successful, what difference will it make?

5. What are the risks?

6. How much will it cost?

7. How long will it take?

8. What are the mid-term and final "exams" to check for success?

Fig. 5: The Heilmeier Catechism [2].

students crossing between methods so it is important that project supervisors provide resources, training and support to enable the flexible use of all three tools, including commercial CAD (computer-aided design), FEA (finite element analysis) and CFD packages. In recent years cost and time barriers limiting experimental research have fallen. The S-duct project discussed in this paper shows that additive manufacturing can be used to make aerodynamic test facilities that can give results of publishable quality in a time scale of weeks and a cost of order $£ 1000$.

Small, focused teams. The final principle is to work in small teams focused on specific research problems so that skills and knowledge are shared and motivation maintained through collective endeavour. Rather than the conventional studentsupervisor pairing, these projects have been run with a small team consisting of two students and two supervisors, with a third academic not responsible for teaching also lending technical support. Where possible the students work on complimentary projects which contribute towards different aspects of the same overall goal. This improves the quality of project meetings as the extra points of view and 'cross-pollination' when reviewing progress often reveal new ideas which may otherwise have been missed. Projects are selected carefully, however, so that there is no direct overlap between the students' work. This means that challenges around competition or fairness of assessment are avoided. Learning to work in teams is also an important skill for both students and academics and weekly meetings help to develop presentation, listening and discussion skills. Overall, the sense of team effort motivates both the students and supervisors and helps to build a sense that the projects are contributing to a larger goal.

\section{Industrial Collaboration}

Industrial collaboration is a central aspect of this work and the projects rely on RE's involvement: they provide research questions on which the projects are built, their funding pays for summer projects and covers CFD and experimental costs, and contact with an innovative UK aerospace company provides motivation. Despite the importance of industrial interaction, papers describing similar projects $[14,15,17]$ do not explain how the industrial-academic relationship is developed or what makes the collaborations successful. Kunttu [22] commented in 2017 that: "Educational collaboration taking place as a part of university-industry research ... is an almost neglected topic". In this section an established methodology for IndustryUniversity collaboration is updated with recommendations for University partners.

Pertuze et al. [3] consider how companies can achieve impact through the use of best practice in Industry-University collaboration. Their article is based on a survey of around 100 projects at 25 multi-national companies and results in a list of 'Seven Keys to Collaboration Success'. These best-practices are written for industry participants to follow but they are mirrored by the way the Whittle Laboratory has approached the relationship with RE. Figure 6 reproduces the seven 
keys identified by Pertuze et al. (left column) and matches them with the most important steps for a University partner to follow (right column). These steps are distilled from the experience of running multi-year student projects with RE and are described in more detail below:

1. Select projects with industrial impact and academic interest. Selecting the research topic is a collaborative exercise carried out with the industrial partner. Project outputs should have impact with the sponsoring company and also be suitable for assessment for the Master's degree. Issues around Intellectual Property (IP) and confidentiality should be addressed while selecting projects, not after.

2. Form small academic teams with complimentary knowledge and skills. The Whittle Laboratory team involved in these projects has expertise in compressor and turbine aerodynamics, CFD and experimental methods and are all committed to combining teaching, research and industrial collaboration. In the first year of running projects support was also provided by experienced senior academic staff.

3. Share teaching and research approach with industrial partner. It is important to have an open dialogue about the benefits and challenges of including novel research in student projects. Both partners have acknowledged two key tenets since the start of the collaboration: First, the supervisors' primary responsibility is to the students' education and second, the project report has to be the student's own work, thus the possibility of the project not being completed successfully is a risk that the industrial partner has to bear. Projects are carefully selected which have impact for RE but which are not on a 'critical path' for the development of SABRE.

4. Invest in long-term relationships. Each student project lasts one year, however, the research topics and level of funding are discussed and planned over multi-year time frames. Papers by Gertner et al. [23] and Thune [24] emphasise the importance of personal relationships in the success of Industry-University collaboration. By maintaining the same small team of Whittle Laboratory academics and RE research managers since 2017, both sides have learned together and trust has been established.

5. Establish strong communication links. Formal and informal communication routines have developed naturally. More formal types of communication with RE, such as termly student presentations and interim and final reports give the student project structure and provide added motivation with tangible deadlines. Discussions between RE and the students is kept to these sessions so that the student role in communication can be clearly defined. More informal communication such as email, telephone and video meetings between the academic supervisors and industry manager occur every 2-3 weeks and are used for regular progress updates and discussion of future work. The industry contact is a project manager who has in-depth technical knowledge and previous experience working in academia.

6. Listen carefully and work to align projects with company needs. Face-to-face meetings include presentations by the academic supervisors with ideas for future research and from RE staff with progress updates on SABRE. Discussions around these topics include RE staff not regularly involved in the projects and help to keep the collaboration aligned with company needs.

7. Look for opportunities to publish after student projects finish. During the projects there is no time to write an academic paper and this would not be considered in the student's assessment for the year. However, students, especially those continuing to post-graduate study, are keen to publish their work and they have been supported in this by the academic supervisors after the educational aspect of the projects have officially been completed.

Barriers to Industry-University collaboration are studied by Bruneel et al. [25] based on a survey carried out across 600 
The Seven Keys to Collaboration Success

Industry

1. Define the projects strategic context as part of the selection process

Select boundary-spanning project managers

Share vision of how collaboration can help the company

4.

6. Build broad awareness of project within the company

Support work internally during and after, until research can be exploited

\section{University}

Select projects with industrial impact and academic interest

Form small academic teams with complimentary knowledge and skills

Share teaching and research

approach with industrial partner

Invest in long-term relationships

Establish strong communication links

Listen carefully and work to alig projects with company needs

Look for opportunities to publish after

student projects finish

Fig. 6: The seven keys to collaboration success for industry summarised from Pertuze et al. [3] (left) and university partners (right).

organisations in the UK. Barriers are categorised as either 'orientation-related', where there is tension between the different priorities of companies and universities, or 'transaction-related', where there are challenges with Intellectual Property (IP) management or dealing with university administration. To minimise the transaction-related barriers the collaboration has focused on understanding the physics of the design space and constraints involved in SABRE's turbomachinery, rather than on specific geometry or software development, and RE have provided representative values for the SABRE cycle, rather than exact figures used in its design. The Lessons Learned section explains how this type of project benefits the industrial partner without generating IP.

Another transaction-related barrier can be funding, however, acknowledgement by the industrial partner that the outcome of student projects is not guaranteed is reflected in the cost of the projects: RE fund computational and experimental costs, typically $£ 3,000-5,000$ per project per year and the optional Whittle Laboratory 8-week summer vacation project which costs around $£ 3,000$. No costs are charged for the masters studentship. The total cost of the six projects described in this paper is $£ 45,000$.

Bruneel et al. conclude that the most effective way to reduce both sets of barriers is to build trust between the partners and this underlying principal, along with a pragmatic approach to IP and funding, can be seen running through the approach presented in Fig. 6.

\section{PROJECT CYCLE}

An annual project cycle, shown in Fig. 7, has been established which integrates the teaching, research and collaboration approaches. This section describes each activity in the cycle.

\section{Project Selection}

Discussions about future projects begin in December, at the end of the first term of the academic year. By mid-January the area of research is agreed with RE so that the projects can be advertised to students.

Ideas for projects are generated through discussion of the technical challenges facing RE engineers and these ideas are then assessed for their suitability as student projects using the following criteria:

- Will it have impact for RE and development of SABRE? 
- Will the student be able to write a project report which meets the requirements needed for assessment?

- Can the 'Heilmeier Catechism' questions be answered clearly and concisely?

- Is it feasible for a Masters Project and are the experimental or computational resources required available?

- Is it an academically interesting project which has the potential to be published?

When deciding future topics of research careful consideration is made to whether a current project should be extended to another year. This has been successful when the current project has had too many avenues for one student to pursue in a single year. In these cases it is important to ensure that original research questions can still be pursued so that academic quality is maintained and new results can be produced for RE.

Having agreed project topics and expected outcomes the academic supervisors write a one-page project proposal. This is based on the Heilmeier Catechism and includes a list of costs. Once agreed these documents become 'Statements of Work' for the contracts that confirm funding and payment schedules.

\section{Student Selection}

The CUED process for student selection begins in the last week of January, at the start of the second term, when project descriptions are posted online for third year students to consider. These give an outline of the project and encourage students interested in the work to contact the supervisors to arrange a meeting and provide a CV.

Students typically choose four or five different supervisors to discuss potential projects and the projects with RE have proved particular popular: in 2019 there were 15 students interested in the two RE projects. During the meetings, which usually last 20-30 minutes, the supervisors explain the project and encourage the students to ask questions and make connections between the third year courses they are studying and the research in the project. The students are then selected based on their:

- Academic record in first and second year.

- Enthusiasm for the project and ability to pick-up new ideas, make connections and ask good questions during the faceto-face meeting.

- Experience relevant to the projects, e.g. previous work with computational modelling or with experimental methods.

The students selected are offered the project and if they accept, sign a CUED 'Project Agreement Form' which confirms the choice. The RE projects are over-subscribed each year and feedback from students suggests this is due to RE's involvement and the exciting application being studied. The consequence is that students with strong academic records, i.e. high II.1 or Ist class marks, an enthusiasm for the topic, and relevant previous experience, have been chosen to undertake the projects.

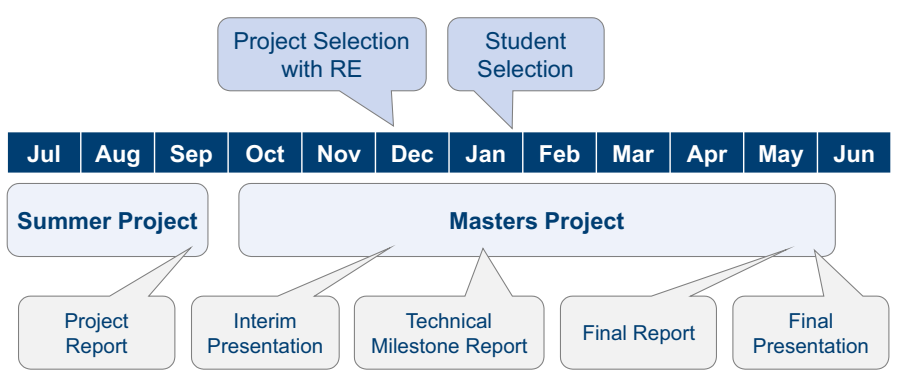

Fig. 7: Annual Project Cycle. 


\section{Optional Summer Project}

RE funding means that summer vacation projects at the Whittle Laboratory, called UROPs (Undergraduate Research Opportunity Programme), can be undertaken before the Masters Project begins. The cost of an 8-week UROP to REL is approximately $£ 3,000$. Availability to participate in the UROP is not considered during student selection, however, take-up of the summer project has been popular: five of the six students selected for the masters project have also done the UROP.

The research carried out during the UROP is linked, but separate to, the Masters project work and is documented in a short report. This provides a clear starting point for assessment of the Fourth Year Project so that the UROP does not give a 'headstart' to the student, however, there are a number of benefits:

- Students become familiar with working at the Whittle Laboratory and establish relationships with each other, the supervisors, other researchers and workshop technicians.

- The supervisors can begin to instil the teaching and research approaches at a time of year when both students and supervisors are less busy than during term.

- RE receive a written report and presentation at the end of the UROP project which gives interim results and the opportunity to discuss and influence the direction of the subsequent 4th Year Project.

\section{Masters Project}

The Masters Projects run for a full academic year from the first week in October to the first week of June. During term, students have weekly 1-hour meetings with the supervisors as well as shorter, more informal contact every 1-2 days to discuss questions and solve problems. At the end of the first term the students deliver a 15 minute interim presentation describing the motivation and aims of the project, results and progress, and a plan for the rest of the work.

In the second term, as well as continuing with weekly meetings, the students have to submit a 6-page 'Technical Mile-

stone Report'. The supervisor provides feedback on a draft version of this report which helps to refine the student's technical report writing skills.

There is less time for project work in the third term because the students also have an exam period in the first two weeks. Throughout the project, the supervisor and student discuss how to balance project work with lecture material, coursework and exams and the split is expected to be approximately 50\% course material and 50\% project.

Before beginning to write the final report, which is limited to 50 pages, the supervisor and student discuss its structure, the main findings and what conclusions can be drawn. The supervisor also provides feedback on a draft of the report around 10 days before it is submitted. After submission, a final presentation is given to the other students and supervisors working on fourth year projects at the Whittle Laboratory.

\section{Assessment}

Fourth Year Project students are assessed throughout the year based on a CUED mark scheme as follows:

- Progress and industry marks worth approximately $20 \%$ of the overall mark are awarded mid way through and at the end of the first and second terms by the project supervisor.

- Marks for oral presentation are awarded at the end of the first and third term and are worth $5 \%$ and $10 \%$ of the total respectively. 
- $10 \%$ of overall marks are given for the technical milestone report submitted at the start of the second term. The report is assessed by the project supervisor and a second academic from the Whittle Laboratory not involved in RE projects.

- The final project report is worth $55 \%$ of the total and is marked by the project supervisor and the same second academic from the Whittle Laboratory that marks the technical milestone report.

Industry partners are not involved in project assessment. The combination of formative and summative assessment motivates the student to work throughout the project and results in a thorough and fair reflection of students' overall achievement.

\section{Project Administration}

Administrative tasks for the academic supervisors can be split into those relating to teaching and those managing the collaboration with the industrial partner; the students are not involved in these processes. For teaching, the supervisors are responsible for submitting various forms and marks to the CUED 'Teaching Office' which administers the student selection process, project agreement, lab access and inductions, and collation of assessment marks.

Industrial collaboration support is provided by the 'Research Office' who register projects, set up an account which can be charged and handle invoicing. They also feed into the University's contract department which negotiate and sign contracts and non-disclosure agreements with sponsoring companies. One of the academic supervisors ensures that project agreements, payment schedules and invoices are completed correctly. In the first year this was time consuming but subsequent project setup has become easier as communication has improved on all sides and lessons are learned from previous years.

\section{PROJECT DESCRIPTIONS}

This section provides brief descriptions of the six research projects undertaken with RE including the research questions, approach and outcomes.

Aggressive S-shaped Ducts. SABRE requires turbomachinery that is substantially lighter than any aerospace or ground based gas turbine. In these projects two students worked to reduce the length of the inter-spool swan-neck duct in the compressor. By including a circumferential 'splitter' blade they showed that it was possible to create a successful design $30 \%$ shorter than current aerospace models.

The work was conducted over the course of two years. The first student undertook a UROP where he developed a TABU [26] optimisation method to generate and simulate duct designs with two-dimensional CFD. The masters project, undertaken in 2017-18, continued the work by investigating trade-offs between loss and duct length for conventional and 'splittered' designs as well as building an experiment to verify the CFD models. In the second year, the student furthered the work with an improved, larger scale sector experiment with increased Reynolds number. This rig, along with three-dimensional CFD, was used to demonstrate the sources of loss within the duct and confirm the benefits of splitters when coupled with a thick structural strut, Fig. 8. In the summer after the second student had completed the work, further CFD cases were run by the academic supervisor and the projects were reported in a paper presented at ASME TurboExpo 2020 [27].

Helium Turbine Design. The SABRE thermodynamic cycle has an air compressor coupled with a turbine operating on a closed loop of pressurised Helium. The current aim to use an 'off-the-shelf' aero-engine air compressor fixes the shaft speed of the turbine at a value that is below optimal and this leads to an unusual turbine design problem which has not been widely studied in the turbomachinery literature.

The first project on this topic, undertaken in $2017-18$, focused on the potential use of a stator-less counter rotating 
turbine. The main research questions were "How should counter rotating machines be designed?" and "What performance benefit can counter rotating machines give over conventional machines?" By using design parameters that are defined in the reference frame of the first blade, within a two blade pair, both conventional and counter rotating machines collapse on to the same design space and can be designed and compared using the same methods. The outcome of the project was a framework which enabled a fair comparison of conventional and counter rotating machines; the findings were published at ASME TurboExpo in 2019 [28] and Fig. 9 shows a comparison between matched counter-rotating and conventional machines. Finally, it was confirmed that from an aerodynamic perspective a counter rotating turbine would act in the same way as a 2:1 gearbox, alleviating the speed mis-match problem in SABRE.

The next part of the work focused on the design of a conventional turbine that could operate with the prescribed condi-

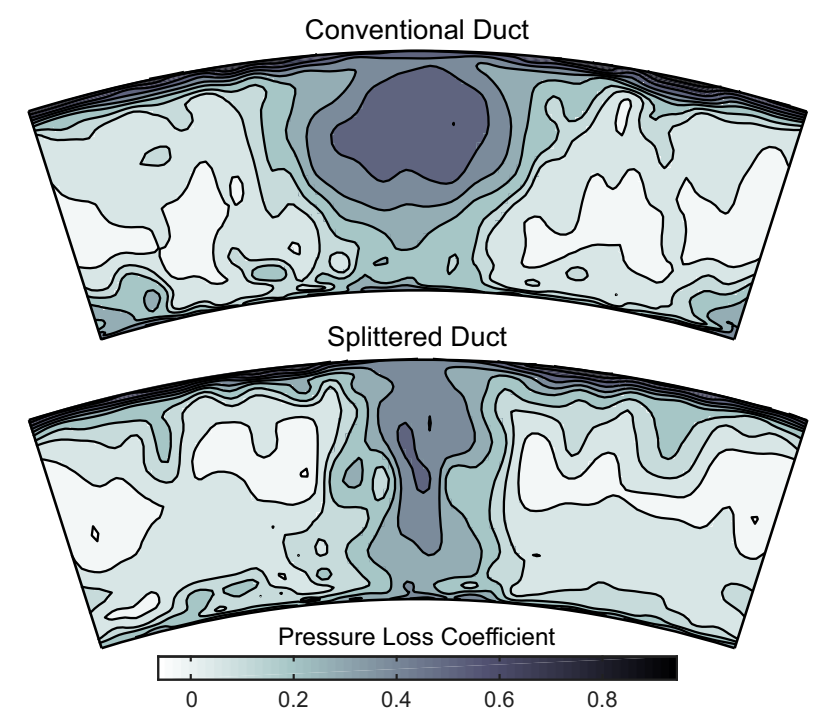

Fig. 8: Experimental traverses at duct exit showing pressure loss coefficient of conventional duct (top) and the splittered duct design (bottom). The loss downstream of the structural strut is significantly improved and total loss coefficient is reduced by $20 \%[27]$.
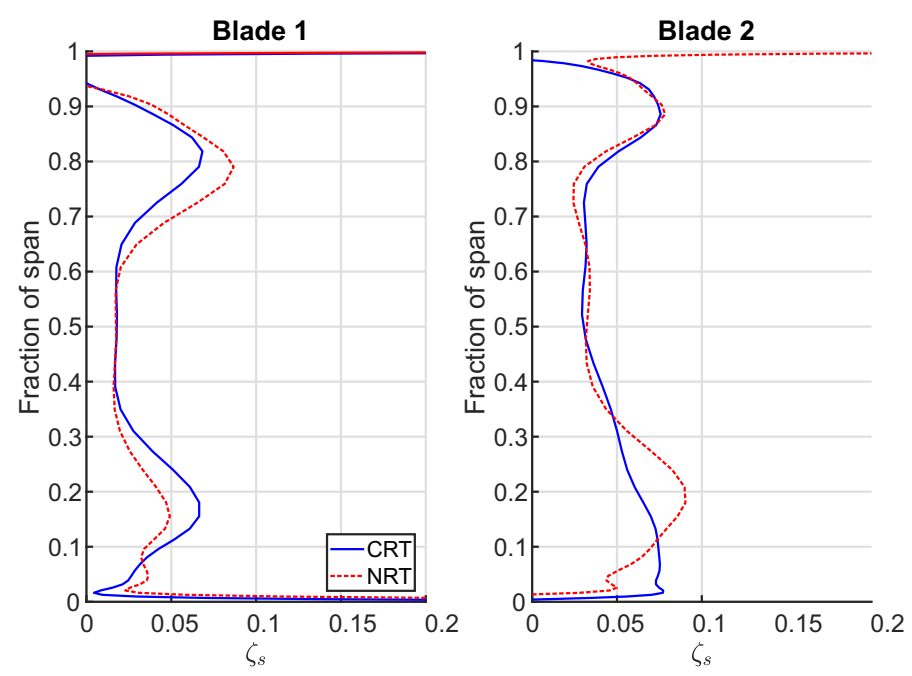

Fig. 9: Spanwise loss coefficient distributions for matched counter rotating (CRT) and conventional machines (NRT) across a two blade pair. Overall efficiency of CRT is 0.2 percentage points higher than NRT [28]. 
tions found in the SABRE cycle which include low volumetric Helium flow rate and fixed shaft speed. Aerodynamic aspects of the problem were studied by a UROP student in Summer 2018 and two subsequent masters project students in 2018-19 and 2019-20. In 2019-20 a project was also undertaken to study the mechanical feasibility of the aerodynamic design. The initial UROP student developed a mean-line model incorporating correlations for the loss sources present. Over the 8-week summer project it was determined that conventional designs would suffer significantly from tip or over shroud losses and that the best way to mitigate this would be to increase shaft speed using a gearbox. The student also produced initial turbine designs that met the operating conditions required.

The 2018-19 masters student continued the analysis by developing a programme to convert mean-line designs into CFD meshes which included shroud leakage paths. This was used to simulate a number of designs which validated the loss breakdown output from the low order models in the mean-line design tool. Good agreement was achieved and this confirmed that over shroud leakage is the dominant loss mechanism in the SABRE Helium turbine. The 2019-20 student studying aerodynamics built on these findings by further developing the loss correlations in the mean-line model and finalising the multi-stage parameterisation of a turbine. Optimisation routines were then used to find optimal designs for differing stage counts from 5 to 25 stages. It was found that optimal performance was achieved with many stages $(>10)$ as this alleviates the tip loss by increasing the span of the blades.

The 2019-20 student studying the mechanical feasibility of the Helium turbine design addressed two research questions: "Can small shrouded blade passages be made in single bladed discs or rings?" and "How does stage count and turbine design affect rotor dynamics?" For the first question a programme was written to calculate CNC (computer numerical control) milling tool paths for the parameterised turbine designs produced by the aerodynamics project. This was used to evaluate the feasibility of manufacture through tool access and aspect ratio and then to calculate and compare manufacturing time for different designs. For the second question a model for the dynamic vibration of the turbine, based on a discrete mass-beam system, was developed for different designs output by the aerodynamic optimisation. Results showed that the many-stage $(>10)$ turbines are feasible given appropriate bearing arrangement and stiffness.

\section{IMPACT AND LESSONS LEARNED}

Feedback from the students, the RE project manager and academic supervisors demonstrate the impact of the projects in terms of education, industrial collaboration and research. In this section the students' views of the work are considered and illustrated with quotes, the RE manager reflects on the collaboration and its impact, and the experience of the academic supervisors is discussed.

\section{Students}

All of the students involved in the projects replied to the request for feedback. Three are now working as engineers in industry with Airbus Defence and Space, the UK Atomic Energy Authority, and The Technology Partnership, an engineering consultancy. The other students are PhD candidates in the Department of Engineering at the University of Cambridge.

The students were asked to reflect on their experience of the projects through five questions:

- What did you enjoy most about the project?

- How do you think the project could have been improved?

- How do you think your project was affected by the involvement of an industrial sponsor? 
Career Choices. For the students who decided to undertake PhDs, the 4th Year Projects strengthened or confirmed their choice at the time that they were making their applications. Alternatively, one of the students commented that it helped him to make the decision not to begin a $\mathrm{PhD}$ as he realised it was not the type of work he was looking for.

For the students who went into industry the 4th Year Project experience confirmed that they would enjoy the challenges of engineering in the real world. It also increased their confidence in both modelling and practical aspects of engineering and they felt it helped with job applications and interviews.

"It helped to make continuing on in
$\begin{gathered}\text { "The experience helped me to realise that I } \\ \text { a realistic and desirable option" }\end{gathered}$
$\begin{gathered}\text { didn't want to undertake a PhD, the nature of } \\ \text { the work wasn't what I was looking for. It did } \\ \text { make me aware that I was interested in the } \\ \text { "I don't think I would have had any and the collaboration aspect of } \\ \text { confidence in my practical capability if it }\end{gathered}$
$\begin{gathered}\text { wasn't for the experimental work I did at well as the technical side" } \\ \text { the end of my project" }\end{gathered}$

Useful Learning. The students now studying PhDs highlight the research approach that they learned during the 4th Year Project which they are able to apply to different problems. The students who went on to work in industry each took away different lessons: One commented on the approach to modelling they learned which looks to build up complexity with the aim of furthering physical understanding, another took away the importance of comparing theory with experiments, and a third is putting to use the communication skills developed and the ability to ask the 'right question'.

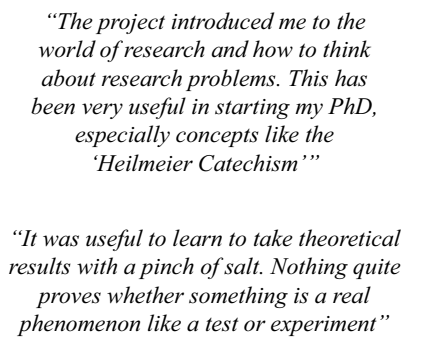

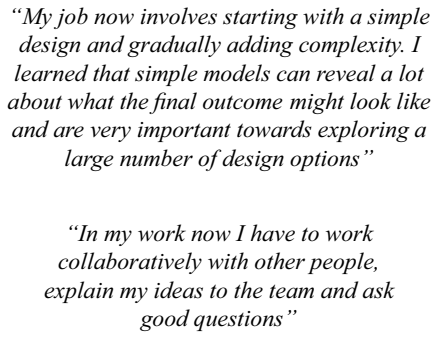

In summary, all of the students enjoyed the projects and are now pursuing careers in engineering. They also recognised the importance of RE's involvement and have experiences which they are taking forward into their current roles in industry and academia.

\section{Industrial Partner}

In this section the experiences of the industrial partner are examined by the RE project manager for the research collaboration.

Projects with industry-university collaboration represent a great opportunity for students to experience the industrial world. Whatever the level of engagement, it must be considered a serious commitment from all three parties involved: students, academic supervisors and industry partners.

For students considering their career plans, these projects represent an invaluable experience to see how a 'real problem' is addressed from both the academic and industrial angles. Students should be encouraged to observe the dynamics between people and to be polite yet inquisitive asking as many questions as possible to both their academic supervisor and the industrial mentor. Good academic and industrial mentoring comes from asking "Which experience would I want to gain if I was in the student's position?". This approach has helped to drive the collaboration between RE and the Whittle Laboratory and has helped to ensure that the students are interested and engaged by the work. 
The other reason the industrial collaboration between RE and the University of Cambridge has been successful is that the student, supervisor and industrial partner's motivations have been aligned. As an industrial collaborator the reasons to work with a university partner is multi-faceted. The following is a list of reasons from the RE perspective which also includes examples of how it helps the business:

- University academics own research methodology and substantial scientific knowledge. For example, RE are interested in advanced turbomachinery aerodynamics as this directly impacts the economics of SABRE. The Whittle Laboratory projects examined two such technologies: aggressive compressor S-ducts [27] and counter-rotating turbines [28]. This research was well received by RE and has helped to conceptualise solutions for SABRE.

- Academics are exposed to different industries and sectors so perhaps there is the potential for spillover knowledge which can be learned from. For example, Whittle Laboratory expertise in blade manufacture has been leveraged by the student project to investigate the relationship between turbine aerodynamic design and manufacturing feasibility and cost.

- University partners encourage industry to reflect on and perhaps deconstruct processes, in other words, to 'think out of the box'. RE has used the Whittle Laboratory collaboration to 'double check our homework' where an academic approach and solution to a problem is compared with in-house solutions, optimised around technological limitations or existing hardware. This is valuable as the University 'sits away' from the daily discussions and may approach the problem from another angle. Experience has shown that the different approaches usually give similar answers, however, it is always useful to understand the different methodologies and physical explanation of the results.

- The students are generally enthusiastic and if motivated tend to produce much more than they are asked to do. They also have specific skills, for example in programming, that the industrial collaborator might need or be able to learn from.

- This type of collaboration is a true investment for the future as it teaches and trains the next generation of engineers. If the students receive a job offer from us, then the project has provided initial training and if they move on having had a good experience, then there is a benefit to the wider engineering sector.

- The collaboration offers a relatively cost-effective research opportunity and is a good way to promote RE within the University and wider industry and academic communities.

\section{Supervisors}

The research projects have been supervised by three early career academics with assistance from two established lecturers. Working as a team, the early career academics lead fundraising, administration, teaching, research and collaboration with RE on the projects. This has allowed them to broaden their teaching skills and develop professional qualities which can only be achieved through experience of managing real research projects.

For all three academics the most important skill learned has been balancing the sometimes competing, sometimes complimentary needs of the students and industry partner. The supervisor's primary responsibility is to the student so they need to bridge the gap between the immediate needs of the industrial sponsor and the academic goals of the project. Communication about changing priorities from the industrial partner are therefore filtered through the supervisor. Achieving the correct balance is an ongoing challenge and there is an unavailable tension between the necessary bias towards teaching requirements and the students' desire for greater interaction with RE.

Ensuring that the project is useful to the industrial partner requires careful management, negotiation and scientific judgement, especially at the start of the project and it should be emphasised that these projects are handled differently to 
contracted research that might be done by a post-doctoral researcher or similar. This paper attempts to capture an approach which, it is hoped, will help others successfully combine student projects with industry collaboration.

The benefits of supervising this type of work outweigh the challenges. Being able to work on an industrially funded project, with a UK-based company, working on technologically advanced products, is an attractive opportunity for an undergraduate student. This means that competition for project places is strong and the students selected are well motivated and have excellent academic records. As a result the quality of research done within the project is high, results can be published and the status and prestige of 'doing good science' is conferred upon the supervisors by their department and wider institution.

The experience of managing the full project cycle is also an invaluable experience for early career academics seeking to build their leadership skills. It is hoped that the positive outcomes presented in this paper encourage others to set up masters student research projects with industrial collaboration.

\section{CONCLUSIONS}

An approach for student research projects with industrial collaboration has been presented. This approach aims to maximise educational benefit to the students, provide useful results for the industrial partner, and engage and motivate the academics supervising the work. This is achieved by combining and adapting established practices in Teaching Pedagogy, Industrial-Academic Collaboration and Research Methodology. Four conclusions are drawn that summarise why the projects have been successful:

1. Student projects with 'novel problems', where answers to research questions are not known $a$ priori, are best suited to research collaborations with industry. Feedback from student, academic and industry participants shows that these projects motivate everyone involved and ensures that all partners benefit from the work.

2. The teaching approach is informed by Kolb's Experiential Learning Cycle. Academic supervisors ensure that students receive adequate support early in the project to help them pass quickly around the four stages of learning: Experience, Observation and Reflection, Concept Forming, and Planning Next Steps. After six to eight weeks it is observed that students are able to 'self-sustain' the cycle so that progress increases and decisions about findings and next steps can be made independently.

3. The projects are carefully planned in consultation with the industrial partner and the 'Heilmeier Catechism' is used to define suitable research questions. Keeping experiments and simulations as simple as possible, using the correct tools, and iterating fast will yield more understanding and improve motivation for the small team working on the project. This is reflected in the positive feedback from the students about the type of work undertaken in their projects.

4. The relationship between university and industry partners has developed throughout the collaboration and is built on good communication and trust. Pertuze et al. provide a list of recommendations for industry partners engaging in collaborations with universities and by mirroring these for the academic partner, an approach has been established which guides the work as projects are selected, undertaken and completed.

This approach has ensured that the project aims have been met: student feedback is positive and all of the students are now pursuing careers in engineering, either in industry or academia; the academic supervisors are motivated by the work, benefit from the experience of managing the research collaboration and have been able to publish papers describing the work; 
finally, this paper shows that motivated masters students have produced useful results for Reaction Engines which have fed into the design of SABRE.

\section{ACKNOWLEDGEMENTS}

The authors would like to thank Reaction Engines for their contribution to the work and in particular Philippa Davies, Osama Lotfi, Kathryn Evans, Marc Arstall and Mark Thomas for their involvement in the collaboration. They are grateful to Prof. Rob Miller and Prof. Graham Pullan for their support and guidance while co-supervising the student projects. Finally, the authors would also like to express their sincere gratitude to the students involved: Arthur Dunlop, Jonathan Waldren, Shail Desai, Nathan Clark, Fergus Flanagan, Will Davis and Zak Karimjee.

\section{References}

[1] Kolb, D. A., 2014. "Experiential Learning: Experience as the Source of Learning and Development." Pearson Education.

[2] Shapiro, J., 1994. “George H. Heilmeier.” IEEE Spectrum, 31(6), pp. 56-59.

[3] Pertuze, J., Greitzer, E. M., Calder, E., and Lucas, W. A., 2010. "Best Practices for Industry-University Collaboration." MIT Sloan Management Review, 51(4), pp. 83.

[4] Bond, A., and Varvill, R., 2018. "Engine Comprising a Rocket Combustion Chamber and a Heat Exchanger." US Patent 10,012,177.

[5] Rumpfkeil, M. P., Turner, M. G., Van Kuren, J. T., Roberts, R., Bons, J., Smith, T., and Ausserer, J. K., 2013. "Thrust Vectoring Design Project at Six Universities: Part ii) Impact on Student Learning and Lessons Learned.” In ASME Turbo Expo 2013: Power for Land, Sea and Air.

[6] Vo, H. D., and Trepanier, J. Y., 2015. "Undergraduate Project in Compressor Rig Design, Fabrication and Testing for Complete Engineering Training." In ASME Turbo Expo 2015: Power for Land, Sea and Air.

[7] Wisler, D. C., 2013. "Engineering: What You Don't Necessarily Learn in School.” In ASME Turbo Expo 2003: Power for Land, Sea and Air.

[8] Pullen, K., Court, A., and Besant, C., 1998. "The Advanced Turbogenerator Project - A Total Technology Education Experience for Engineering Undergraduate Students." In ASME Turbo Expo 1998: Power for Land, Sea and Air.

[9] Mund, F. C., Kalfas, A. I., Abhari, R. S., Turcan, Y., Hourmouziadis, J., Trebinjac, I., and Vouillarmet, A., 2003. “A Multi-component and Multi-disciplinary Student Design Project within an International Academic and Industrial collaboration." In ASME Turbo Expo 2003: Power for Land, Sea and Air.

[10] Templalexis, I., Lekas, T., Koutsomichalis, A., and Kalfas, A., 2016. "Unmanned Air Vehicle Interdisciplinary Design Project." In ASME Turbo Expo 2016: Power for Land, Sea and Air.

[11] Turner, M. G., Rumpfkeil, M. P., VanKuren, J. T., Roberts, R. A., Bons, J., Smith, T., Ausserer, J. K., and Litke, P., 2013. "Thrust Vectoring Design Project at Six Universities: Part i) Project Description and Final Designs.” In ASME Turbo Expo 2013: Power for Land, Sea and Air.

[12] Byerley, A. R., Rolling, A. J., and Van Treuren, K. W., 2013. "Estimating Gas Turbine Engine Weight, Costs, and Development Time During the Preliminary Aircraft Engine Design Process." In ASME Turbo Expo 2013: Power for Land, Sea and Air. 
[13] Kyprianidis, K. G., Gronstedt, T., and Barbosa, J. R., 2012. "Lessons Learned from the Development of Courses on Gas Turbine Multi-disciplinary Conceptual Design.” In ASME Turbo Expo 2012: Power for Land, Sea and Air.

[14] Mirzamoghadam, A. V., and Harding, J. C., 2013. "The Teaching Value of Defining Iterative Design Projects in Serving Capstone Engineering Undergraduate Education.” Journal of Engineering for Gas Turbines and Power, 135(9).

[15] Miller, T., Evanko, J., Camci, C., Glezer, B., and Fox, M., 1999. "A Student-Executed Industrial Gas Turbine Design Project." In ASME Turbo Expo 1999: Power for Land, Sea and Air.

[16] Biba, Y., and Maier, J. A., 2011. "Aerodynamic Design, Analysis, Integration, and Optimization Tool for Centrifugal Compressor OEM." In ASME Turbo Expo 2011: Power for Land, Sea and Air.

[17] Lock, G., Child, M., Cheng, V., Johnson, R., Mezzullo, W., Pattinson, C., Peet, S., and Wright, C., 2006. “An Undergraduate Industrial Design Exercise at Rolls-Royce plc.” In ASME Turbo Expo 2006: Power for Land, Sea and Air.

[18] Acworth, E. B., 2008. "University-Industry Engagement: The Formation of the Knowledge Integration Community (KIC) Model at the Cambridge-MIT Institute.” Research Policy, 37(8), pp. 1241-1254.

[19] Morss, K., and Murray, R., 2005. "Teaching at University: A Guide for Postgraduates and Researchers." Sage.

[20] Biggs, J. B., 2011. "Teaching for Quality Learning at University: What the Student Does." McGraw-Hill Education $(U K)$.

[21] Moon, J. A., 2013. "Reflection in Learning and Professional Development: Theory and Practice." Routledge.

[22] Kunttu, L., 2017. “Educational Involvement in Innovative University-Industry Collaboration.” Technology Innovation Management Review 7(12), 14-22.

[23] Gertner, D., Roberts, J., and Charles, D., 2011. "University-Industry Collaboration: a CoPs Approach to KTPs." Journal of Knowledge Management.

[24] Thune, T., 2007. “University-Industry Collaboration: The Network Embeddedness Approach.” Science and Public Policy,34(3), pp. 158-168.

[25] Bruneel, J., d'Este, P., and Salter, A., 2010. "Investigating the Factors that Diminish the Barriers to University-Industry Collaboration." Research Policy 39(7), pp. 858-868.

[26] Glover, F., 1989 “Tabu Search: Part I.” ORSA Journal on Computing, 1(3), pp. 190-206.

[27] Taylor, J., Flanagan, F., Dunlop, A., Grimshaw, S. D., and Miller, R., 2021. "Super Aggressive S-Ducts for Air Breathing Rocket Engines.” Journal of Turbomachinery, 143(6), 061015.

[28] Waldren, J., Clark, C., Grimshaw, S. D., and Pullan, G., 2019. "Non-Dimensional Parameters for Comparing Conventional and Counter-Rotating Turbomachines." Journal of Turbomachinery, 143(12). 